\title{
OPERATIONAL Modeling: SEMIENClosed BASIN MODELING AT THE NAVAL OCEANOGRAPHIC OFFICE
}

\author{
By C. Horton, M. Clifford, \\ D. Cole, J. Schmitz \\ and L. Kantha
}

$\mathrm{T}$ HE U.S. Naval Oceanographic Office (NAVOCEANO) is developing an operational capability to forecast ocean currents and thermal structure in nearshore regions and semienclosed seas. Development thus far has emphasized semienclosed seas because of the relative ease of defining boundary conditions. The first area for which a modeling system was implemented was the Persian Gulf. Operational use of the modeling system for this area began in November 1990, but the modeling system has continued to evolve and undergo additional testing. We have applied the modeling system developed for the Persian Gulf to two other semienclosed basins, the Red Sea and the Mediterranean, and they are being tested for possible operational use.

Principal elements of the modeling system are: 1) a three-dimensional, primitive-equation circulation model developed originally at Princeton University (Blumberg and Mellor, 1987), 2) temperature, salinity, and bathymetry data bases, and 3) the NORAPS (Navy Operational Regional Atmospheric Prediction System) meteorological forecasts for the Persian Gulf area from the Fleet Numerical Oceanography Center. We also employ a graphics-display and verification software package provided by the Institute for Naval Oceanography (INO) to display our model results. The circulation model was developed originally at Princeton University and Dynalysis of Princeton by G. Mellor, A. Blumberg, H. Herring, L. Kantha, and others. The version of the model we use was optimized at INO to run on a Cray supercomputer. Important characteristics of this model are that it has complete thermodynamics and includes imbedded turbulent-closure submodels, which provide Ekman surface and bottom layers.

C. Horton, M. Clifford, D. Cole, J. Schmitz, Naval Oceanographic Office, Stennis Space Center. MS 39522. USA: L. Kantha. University of Colorado, Boulder, CO 08439, USA.
The model uses terrain-following vertical coordinates, where each level is a fixed fraction of the water depth. Depending on the basin being modeled, between 14 and 22 levels have been used. In all cases the spacing of the levels is reduced near the surface and bottom so that the top and bottom boundary layers are resolved. The present version of the Persian Gulf model uses an along-axis resolution of $8.4 \mathrm{~km}$ and a cross-axis resolution of $7.4 \mathrm{~km}$. The Red Sea model uses along-axis and cross-axis resolutions of 14 and $6 \mathrm{~km}$, respectively. The resolution of the Mediterranean version of the model is $10 \mathrm{~km}$ in both directions.

All model versions are forced with NORAPS meteorological forecasts. NORAPS provides analyzed meteorological fields at 12-hour intervals and forecast fields 48 hours ahead at 6-hour intervals. The fields we use are near-surface winds, air temperatures, and vapor pressures (equivalent to specific humidity). From these fields we derive the surface wind stress and the air-sea heat and salinity fluxes. In doing this we ignore precipitation and assume a fixed cloud fraction, although we plan eventually to use forecast precipitation rates and to estimate cloud fraction automatically from infrared imagery. We also record surface atmospheric pressure and are testing this term as additional forcing for the model.

Running the model requires bathymetry and initial-temperature and salinity fields. The bathymetry we use originates as a 2 -minute resolution field that we smooth to model resolution. When starting the model from rest, we use gridded temperature and salinity fields derived from the Master Oceanographic Observation Data Set, which is a collection of ungridded temperature and salinity profiles from many sources. The gridded temperature and salinity fields were constructed with a horizontal resolution of 20 minutes and then interpolated to model resolution. A temperature field was constructed for each season. In the Persian Gulf, because of a paucity of data,

The first area for
which a modeling
system was
implemented was the
Persian Gulf.



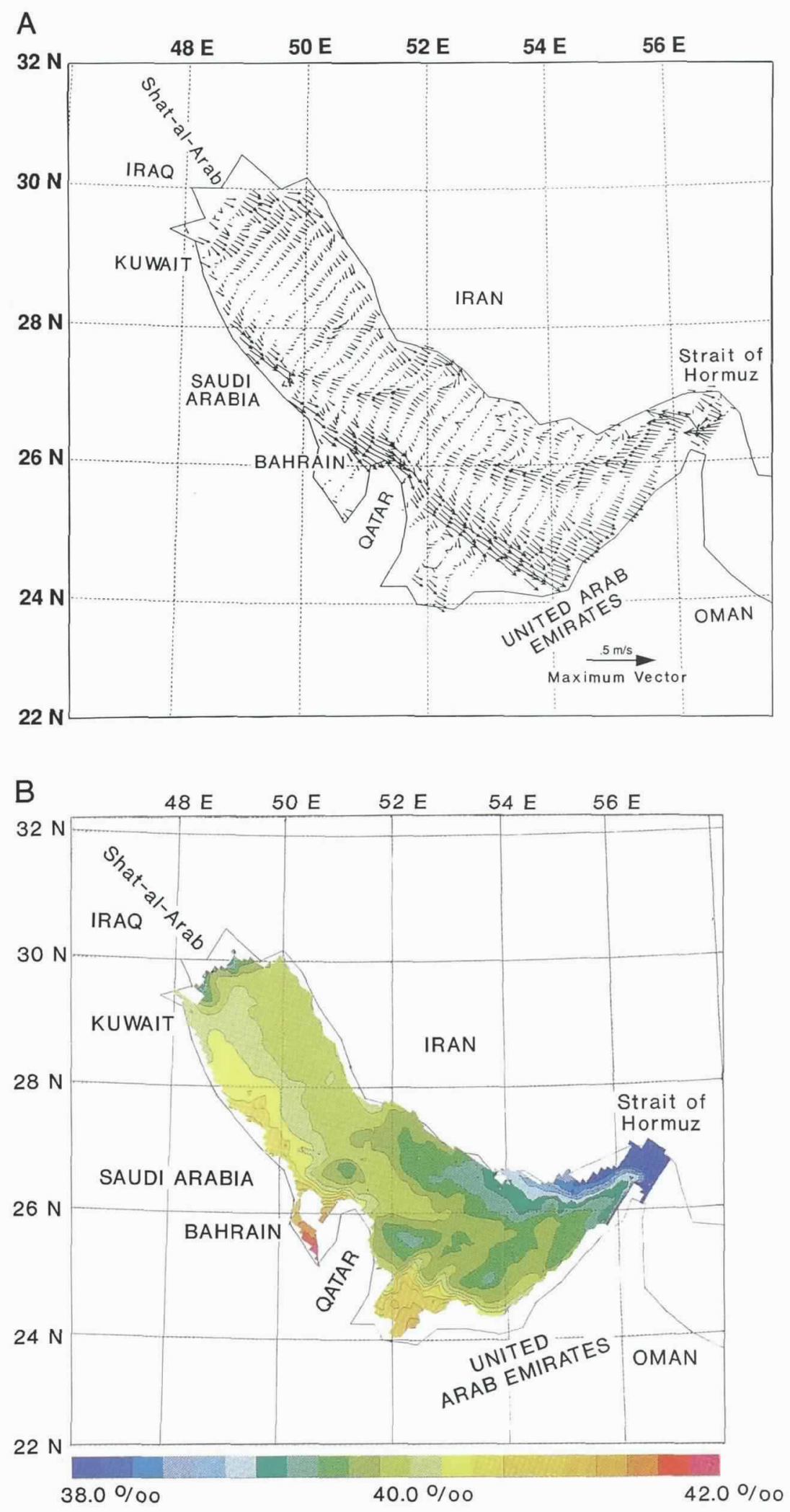

Fig. 1: (A) Predicted surface velocity for the Persian Gulf after 90 days using climatological winds and heat fluxes. (B) Predicted near-bottom salinity for the Persian Gulf after 90 days using climatological winds and heat fluxes.

only an annual-average salinity file was made. At the end of each model run, the temperature, salinity, and velocity fields necessary to initialize the next model run can be saved. Most operational forecasts are initialized in this manner.

\section{Model Predictions}

The Persian Gulf is a shallow, semienclosed basin with a mean depth of only $25-40 \mathrm{~m}$. The circulation of this basin is primarily driven by the local wind stress and secondarily by thermohaline forcing. The prevailing wind in the Persian Gulf is from the northwest and is called a shamal. A monthly climatic atlas shows winds generally down the axis of the Persian Gulf (Meteorological Office, 1949). Mean scalar wind speeds in the center of the Gulf are typically 14 to $22 \mathrm{~m} / \mathrm{s}$. A winddriven generally cyclonic circulation results. However, especially in the winter, the shamal can be interrupted by winds from varying directions. For example, winter storms are preceded by south winds that veer to northwest after the storm passage. This can temporarily reverse the surface circulation. The lands surrounding the Persian Gulf are dry so there is strong excess evaporation over the Persian Gulf. This results in a Mediterraneanstyle thermohaline circulation (Brewer and Dryssen, 1985). Accordingly, at the Strait of Hormuz in our model there is a surface inflow of relatively fresh (37-37.5 ppt) water and an outflow of deeper, more saline (38-39 ppt) water on the southern side.

We show model results for a single scenario. Using essentially yearly averaged winds, down the axis at $5 \mathrm{~m} / \mathrm{s}$, and yearly averaged heat fluxes, we spun up the model for 90 days to nearly steady state. Figure 1A shows the predicted surface velocity. We see the generally cyclonic circulation but with more complexity. Some of the highest current speeds are in the inflow through the southern side of the Strait of Hormuz. The strong inflow along the southern side of the Strait is consistent with a current-speed climatology by Schott (1918). This inflow feeds the eastward coastal current along the south edge of the Gulf, which is strongest near Qatar. Along the Iranian coast, there is another eastward current which terminates at $\sim 51^{\circ} \mathrm{E}$, where its remnant turns south into the interior. Figure $1 \mathrm{~B}$ shows that near-bottom salinities $\sim 40 \mathrm{ppt}$ are predicted in the very shallow coastal areas on both sides of Qatar. The highest value predicted is in the gulf south of Bahrain, where Chandy, et al. (1990) reported hypersaline conditions. At the Strait of Hormuz, we see the Mediterranean-style inflow of relatively fresh water and outflow of more saline water, although most of the inflow is near the surface. A source of fresh water is specified to simulate the outflow from the Shat-al-Arab waterway. The limited effect of this source can be seen at the extreme western edge of the Persian Gulf.

\section{Model Verification}

The model predicts the three-dimensional evolution of the temperature, salinity, and velocity 
fields. However, operational use of the model has been limited to the prediction of near-surface current speeds. As such, testing and evaluation of the modeling system has concentrated on measuring the accuracy of the modeled near-surface velocity fields. To measure this accuracy we have relied on air-deployed, sonobuoy-sized, environmental data buoys that are tracked in near-real-time using System ARGOS. We typically obtain four positions a day per drifter from which we compute the drifter speeds. We study the veracity of our modeling system by comparing predicted and observed drifter speeds. However, modeling the translation of the drifters is not simple because they are subject to substantial wind drag and water drag at more than one depth. We model three main sources of drag: the submerged portions of the instrument housing and flotation bag, the drogue that was usually set at 4-m depth, and wind drag because the ratio of wetted-to-air area for these drifters is only 3.6 .

During March 1991, five drifters were deployed in the northwest Persian Gulf. While two of the drifters quickly went ashore, three of the drifters, as shown in Figure 2, provided long tracks suitable for testing as they moved downstream toward Qatar. Forecast and observed drifter tracks were compared during overlapping 3-day periods. Results are shown separately for the three drifters in Figure 3. The curves shown are normalized distance errors, which were derived from least-square polynomial fits to composites of all the data. Normalized errors in the modeled drifter tracks are obtained by dividing the absolute errors by the distance the drifters actually moved. The absolute errors are obtained by computing the distance between the modeled and observed drifters that started at the same position at the beginning of each 3-day period. When the normalized error is less than one, the model is better than persistence because the model error is less than that obtained by assuming no motion. The results from all three drifters decline to $\sim 0.5$ after 72 hours. The normalized errors, of course, are much closer to one for very short-term predictions, because there is little net motion of the drifters. There were occasions when the model forecasts gave very large normalized errors. These tended to occur when the winds driving the model incorrectly timed frontal passages. Under these conditions the observed and predicted drifter tracks could, for a while, be opposite in direction.

\section{Future Plans}

Upgrading and testing of the modeling system will continue, but the basic configuration of our modeling system for the Persian Gulf is complete. Certainly, we will continue to tune the model to improve our test results. Working with INO, we also hope to improve our ability to display the model outputs to better understand the physics of our forecast fields. However, our modelling

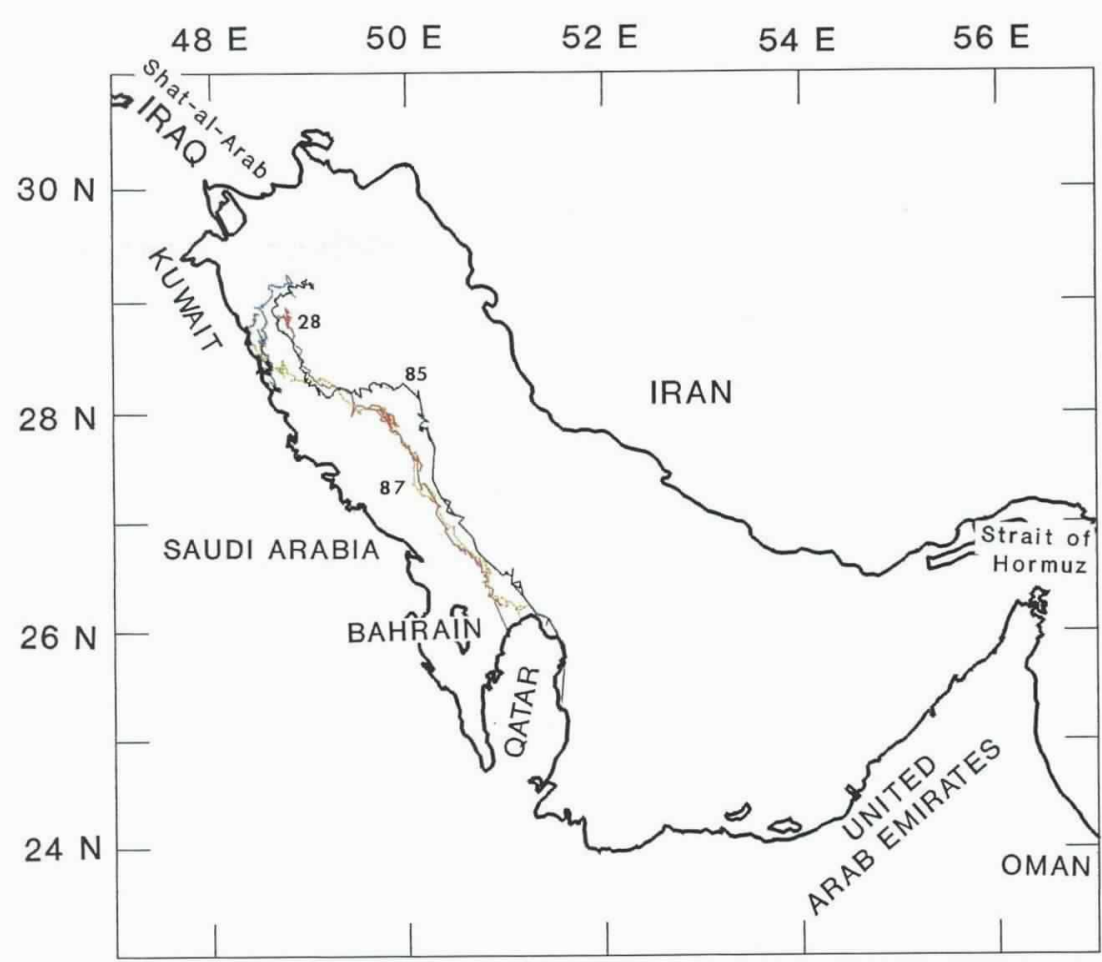

Fig. 2: Drifter tracks used to verify the model.

system is incomplete in the description of the nearsurface physics. The surface boundary-layer submodel only includes Ekman dynamics. Within a distance of the order of the wave height, a zone we are interested in, additional physics needs to be added. Certainly, we need to compute the waveinduced current speeds. We are in the process of implementing a spectral-wave model in the Persian Gulf and other semienclosed basins. By doing this, we hope to compute the sum of the windand wave-induced near-surface drifts.

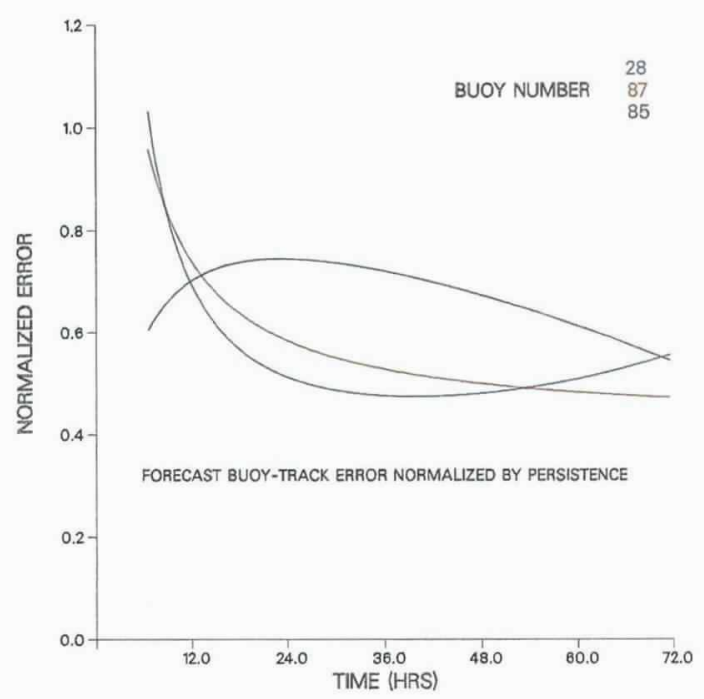

Fig. 3: Forecast errors of drifter tracks normalized by persistence.
We study the

veracity of our

modeling system by

comparing predicted

and observed drifter

speeds. 


\section{References}

Blumberg, A.F. and G.L. Mellor, 1987: A description of a threedimensional coastal circulation model. In: Three-Dimensional Coastal Circulation Models. N. Heaps, ed., American Geophysical Union, Washington DC. 208 pp.

Brewer, P.G. and D. Dryssen, 1985: Chemical oceanography of the Persian Gulf. Prog. Oceanog., 14, 41-55.
Chandy. J.V.. S.L. Coles and A.I. Abozed. 1990: Seasonal cycles of temperature, salinity and water masses in the western Arabian Gulf. Oceanol. Acta. 13, (3), 273-281.

Meteorological Office, 1949. Monthly Meteorological Charts of the Indian Ocean. HMSO, London.

Schott, G.. 1918: Ozeanographie und klimatologie der Persischen Golfes und des Golfes von Oman. Supplement to Annalen der Hyrographie U. Maritimen Meteorologie, 10-12, Berlin. 